Article

\title{
Sensory Processing, Perceived Stress and Burnout Symptoms in a Working Population during the COVID-19 Crisis
}

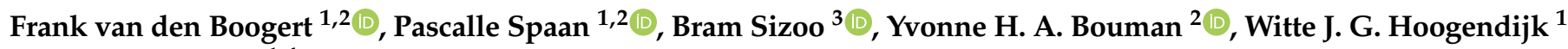 \\ and Sabine J. Roza ${ }^{1,4, *}$
}

1 Department of Psychiatry, Erasmus University Medical Center, 3015 GD Rotterdam, The Netherlands; f.vandenboogert@erasmusmc.nl (F.v.d.B.); p.spaan@erasmusmc.nl (P.S.); w.hoogendijk@erasmusmc.nl (W.J.G.H.)

2 Department of Research, Transfore, 7416 SB Deventer, The Netherlands; y.bouman@transfore.nl

3 Center for Developmental Disorders, Dimence Institute for Mental Health, 7416 SB Deventer, The Netherlands; bram@orcat.nl

4 Netherlands Institute for Forensic Psychiatry and Psychology, 3511 EW Utrecht, The Netherlands

* Correspondence: s.roza@erasmusmc.nl

Citation: van den Boogert, F.; Spaan, P.; Sizoo, B.; Bouman, Y.H.A.;

Hoogendijk, W.J.G.; Roza, S.J.

Sensory Processing, Perceived Stress and Burnout Symptoms in a Working Population during the COVID-19 Crisis. Int. J. Environ. Res. Public Health 2022, 19, 2043. https:// doi.org/10.3390/ijerph19042043

Academic Editors: Inah Kim, Tae-Won Jang, Chunhui Suh and Wanhyung Lee

Received: 10 January 2022

Accepted: 10 February 2022

Published: 11 February 2022

Publisher's Note: MDPI stays neutral with regard to jurisdictional claims in published maps and institutional affiliations.

Copyright: (C) 2022 by the authors. Licensee MDPI, Basel, Switzerland. This article is an open access article distributed under the terms and conditions of the Creative Commons Attribution (CC BY) license (https:/ / creativecommons.org/licenses/by/ $4.0 /)$.

\begin{abstract}
Although previous research suggests an association between sensory processing and perceived stress in a broad spectrum of mental health conditions, it remains unclear whether this phenomenon occurs independently from psychopathology. The present study investigated the association between sensory processing patterns, perceived stress and occupational burnout as a stress-related condition in a working population. We focused on different aspects of sensory processing and used the momentum of a particularly stressful period: during the first months of the global COVID-19 crisis. A total of 116 workers at a mental healthcare institution in The Netherlands completed the Adolescent/Adult Sensory Profile (AASP), the Perceived Stress Scale (PSS-10) and the Burnout Assessment Tool (BAT). Our results demonstrated that higher scores on sensory sensitivity and low registration were associated with higher scores on perceived stress and core burnout symptoms. Sensory hypersensitivity was also associated with more secondary burnout symptoms. Associations were not driven by underlying sensory-related disorders (e.g., ASD or ADHD). In conclusion, sensory processing difficulties are relevant predictors of stress and occupational burnout, also in healthy employees. This phenomenon warrants further attention, as relatively simple adjustments in working environment may possess important preventive effects.
\end{abstract}

Keywords: sensory processing; sensory profile; sensory sensitivity; stress; burnout; COVID-19

\section{Introduction}

Sensory processing is defined as receiving, modulating, integrating and organizing sensory stimuli, and the behavioral response to these stimuli [1]. Within the work environment, this includes the processing of auditory and visual information and other sensory stimuli, underlining the relevance of, for instance, acoustics and lighting. Persons with sensory processing difficulties might miss sound input such as ringing phones or incoming persons, may show humming or whistling in their working environment, or may overreact to colleagues or clients who get to close, etc. In general, humans are neurobiologically programmed to adapt their responses to environmental stimuli, however, variability among the general population is high and some people seem to have more sensitive brains or more difficulties in adapting their behavior to stimuli from their environment. Profound difficulties in sensory processing can be part of several mental health conditions, or may be recognized as a distinct sensory processing disorder (SPD) [2]. Whereas most individuals present a variation in their sensory processing patterns, difficulties in sensory processing might predispose health implications and the development of psychopathology [3]. Neurodevelopmental disorders such as autism spectrum disorder (ASD) and 
attention-deficit/hyperactivity disorder (ADHD) are often associated with sensory processing difficulties-even leading to incorporation of hyper- and hyporeactivity to sensory stimuli in the diagnostic criteria of ASD (DSM-5) [4]. Difficulties in sensory processing are, however, not restricted to individuals with neurodevelopmental disorders, and may be recognized as part of a more transdiagnostic phenomenon.

Sensory processing difficulties have been associated in the healthy population also, with various functional problems. On an emotional level, sensory processing is associated with anxiety level [5], negative affect [6] and distress [7]. Moreover, hypersensitivity is positively correlated with sleeping quality [8] and pain perception [9]. Sensory processing difficulties have been shown to negatively impact well-being, life satisfaction, and quality of life [10]. As such, sensory processing difficulties may interfere with performance and participation in different life contexts, including work. Furthermore, it may well be that sensory processing difficulties drive exaggerated stress responses to environmental stimuli, including work stress.

The possible association between sensory processing and perceived stress has been investigated primarily within the context of psychopathology and, particularly, in neurodevelopmental disorders. In children with ASD, sensory processing is associated with either heightened or lower stress hormone (cortisol) levels, depending on the type of aspect of sensory processing [11]. Hypersensitivity for sensory stimuli, for example, was associated with higher cortisol levels and higher physiological arousal during play activities [12]. In children with ADHD, sensory sensitivity was found to moderate the activity of the hypothalamic-pituitary-adrenal (HPA) axis and to differentiate between subtypes of ADHD [13]. There are also indications that sensory sensitivity is a relevant factor for perceived stress and anxiety in individuals with autistic traits, i.e., also in individuals without a clinical disorder. Whether sensory sensitivity leads to exaggerated stress responses, or exaggerated stress responses leads to sensory sensitivity, is largely unknown [14]. In veterans with acquired exaggerated stress responses due to PTSD, light and noise sensitivity are associated with more avoidance, intrusive experiences and hyperarousal [15]. Also in children, various aspects of sensory processing are found to be associated with posttraumatic stress [16]. Although results from previous research suggest an association between sensory sensitivity and perceived stress in psychopathology, it remains unclear whether sensory processing patterns other than sensory sensitivity, such as sensory seeking or sensory avoiding behaviors or those registered as sensory stimuli [17], are relevant in this context, and whether this phenomenon occurs independently from psychopathology.

A well-known stress-related condition is occupational burnout. In short, this condition can be defined as exhaustion due to prolonged exposure to work-related problems [18]. Although exhaustion is indeed at the symptomatologic core of occupational burnout, Schaufeli, et al. [19] broadened this definition by including other core and additional dimensions: "a work-related state of exhaustion that occurs among employees, which is characterized by extreme tiredness, reduced ability to regulate cognitive and emotional processes, and mental distancing. These four core dimensions of burnout are accompanied by depressed mood as well as by non-specific psychological and psychosomatic complaints". Whether sensory processing difficulties may serve as precursors or markers for occupational burnout, is largely unknown. Some studies described an association of sensory processing sensitivity with burnout $[20,21]$. However, these studies measured the concept of 'sensory processing sensitivity', which represents a proposed personality trait characterized by deeper cognitive processing of stimuli and heightened emotional reactivity, and is conceptually different from (or even unrelated to) the more neurological approach of sense-based processing and related sensory processing disorders (SPD) [22]. In other words, 'being a hypersensitive person' is not the same as 'having sensory processing difficulties', and the other way around. As yet, it is unknown if and how these sensory processing difficulties are part of occupational burnout symptomatology or sequelae.

Sensory processing difficulties can be transient over time and can be measured in detail for each sensory modality separately by fundamentally determining the individual neuro- 
logical threshold (the intensity of sensory stimulation needed to evoke neural response) and the resulting behavioral response to the incoming sensory information [23], without directly taking personality traits, emotional reactivity and depth of cognitive processing into account. In the present study, we focused on this neurological approach, and studied the associations of these detailed modal sensory patterns to the complex symptomatology of perceived (job) stress and occupational burnout. We studied these associations in a (predominantly healthy) working population, however, during the stressful first months of the global COVID-19 crisis, which increased the statistical power to find a meaningful effect on occupational burnout. We hypothesized that the COVID-19 crisis would serve as a general risk factor for burnout, not only in 'front line' health care professionals, but also in other workers, due to higher job demands and lower job positives. Many workers were facing work overload, restricted work environment, and challenges to come up with effective strategies to continue their jobs. At the same time, they were facing lower job positives like enriching social interaction with colleagues and building competence.

\section{Materials and Methods}

\subsection{Study Design}

The Oostwest Project is an observational study in a population of employees at the Dimence Group Mental Health Care Institutions in The Netherlands. The main aim was to study the effects of a changing work situation due to the COVID-19 pandemic, such as the increased working from home and use of telepsychiatry, or social distancing within the work environment. Data were collected between June and August 2020. The project was approved by the institutional review board of Dimence Group (CWO-062020PSFB). All participants provided written informed consent after procedures were fully explained, in accordance with the World Medical Association Declaration of Helsinki. The survey was distributed to each participant using the GemsTracker online survey system. A total of 251 employees received our study information sheet and were invited to participate. After sufficient reflection time, 116 employees $\left(M_{\text {Age }}=44.7, S D_{\text {Age }}=12.2 ; N_{\text {Male }} / N_{\text {Female }}=33 / 83\right)$ agreed to participate in the study. In total, five participants did not complete all four parts of the survey. However, all 116 participants did complete the first part of the survey, including the Work Situation questionnaire as described below.

\subsection{Measurements}

The Adolescent/Adult Sensory Profile (AASP) [17,24,25], a 60-item self-report questionnaire, was used to measure responsiveness to various sensory stimuli and to identify sensory processing difficulties that may hinder daily functioning. The AASP is the most frequently used instrument model for this purpose in adults and adolescents with ASD, however is also suited for use in other populations [26]. The questionnaire produces four continuous subscale scores ranging from 15 to 75 , representing the four quadrants of the Model of Sensory Processing [17,23]: low registration (i.e., under-registration, e.g., missing stimuli such as sound input or slowed responses), sensory seeking, sensory sensitivity, and sensory avoiding. Each subscale consists of 15 items, rated on a 5-point Likert scale from never (1) to always (5). The values of the alpha coefficients for the quadrant scores range between 0.64 to 0.78 [27], which indicates satisfactory internal consistency. Within the present sample, the calculated Cronbach's alpha was 0.84 . We used all four raw quadrant scores for our analyses. Additionally, we calculated an AASP sum score, with a range of 60 to 300. For descriptive purposes, we calculated reference scores based on the data published in the instrument's manual [24].

The 10-item version of the Perceived Stress Scale (PSS-10) [28] was used to measure the degree to which individuals appraise daily life situations in the last month as stressful and consists of items measuring self-efficacy and helplessness. This short version of the PSS has demonstrated high validity and reliability [29,30]. Each item is answered on a Likert scale from 'never' (0) to 'very often' (4). The total score ranged from 0 to 40 , with a higher score indicating greater stress. The perceived helplessness subscale (ranging from 0 to 24) 
and the perceived self-efficacy subscale (ranging from 0 to 16) have been calculated as well. The calculated continuous raw scores were used in our statistical analyses, as described below. For descriptive purposes, the raw scores were compared to the reference data for males and females, as described in the PSS-10 manual [28]. Within the present sample, the calculated Cronbach's alpha was 0.87 .

The Burnout Assessment Tool (BAT) was used to estimate burnout symptomatology [31]. This 33-item self-report questionnaire consists of six different subscales: exhaustion, mental distance, cognitive impairment, emotional impairment, psychological complaints, and psychosomatic complaints. In line with instructions in the manual, the first four core symptoms were interpreted both separately and combined into a core symptoms score. Additionally, the latter two subscales were interpreted separately and combined as a secondary symptoms score. The core symptoms score, secondary symptoms score and the individual subscale scores were compared to the reference group of Flemish workers, as published in the instrument's manual [31]. This resulted in 'no risk', 'at risk' and 'very high risk' scores. The instrument demonstrated adequate reliability, as well as convergent and discriminant validity with other burnout measures [19]. Within the present sample, the calculated Cronbach's alpha was 0.94.

We measured various demographic and work-related variables. The applied educational levels were lower, middle and higher, in line with Dutch governmental guidelines issued by Statistics Netherlands. The lower educational level included primary and special primary education, prevocational education, the first three years of senior general secondary education and pre-university secondary education and the lower secondary vocational training. The middle educational level included the upper secondary education, vocational training and middle management and specialist education. The higher educational level included the associate, bachelor, master and doctoral degrees. These variables were used for sample characteristics and for limitation of confounding effects. We used a self-assembled 15-item Work Situation questionnaire to measure the perceived changes in work situation since the start of the COVID-19 crisis in The Netherlands, in March 2020. All questions were answered on a 5-point Likert scale, ranging from 'strongly decreased' to 'strongly increased'. Data resulting from this questionnaire were solely used for descriptive purposes.

\subsection{Statistical Analysis}

For all statistical analyses, we used IBM SPSS version 25.0 (IBM Corp., New York, NY, USA). For descriptive purposes, means and standard deviations were calculated for continuous covariates, determinants and outcome variables and frequencies for dichotomous variables. In addition, where available, reference group distributions in percentages were calculated for sensory processing and stress- and burnout-related variables. We used multiple linear regression models to analyze the associations of sensory processing (AASP raw quadrant scores and AASP total score) with stress and burnout as outcome variables (PSS perceived stress, BAT core symptoms and BAT secondary symptoms). Secondary analyses were conducted for the more detailed subscale scores of the PSS and BAT. To overcome multicollinearity problems (high condition index values (>30) and unstable b-coefficients) between the four raw quadrants of sensory processing, we applied forward selection as model building strategy. Age, sex, and educational level were standard covariates in the models. In the regression analyses with PSS total and subscale scores as outcome variable, one influential case was excluded due to random answering of this specific questionnaire. All other applicable statistical assumptions were met. Effect sizes of the predictor variables are expressed in Cohen's $f^{2}$, calculated using the $R^{2}$ and $\Delta R^{2}$ of each model and interpreted according to Cohen's guidelines [32].

\section{Results}

\subsection{Descriptive Statistics}

General sample characteristics are presented in Table 1. The majority of participants were female. Most participants were higher educated. A small number of participants 
reported potentially sensory-related conditions, such as a diagnosis of ASD, ADHD, neurological disease or the use of drugs or medications with possible sensory related effects in the last 30 days.

Table 1. General sample characteristics $(n=116)$.

\begin{tabular}{|c|c|c|}
\hline Descriptive & & $\%$ \\
\hline Age (M, SD) & & $44.7(12.2)$ \\
\hline \multirow[t]{2}{*}{ Sex } & Female & 71.6 \\
\hline & Male & 28.4 \\
\hline \multirow[t]{3}{*}{ Educational level } & Lower ${ }^{A}$ & 3.4 \\
\hline & Middle ${ }^{B}$ & 22.4 \\
\hline & Higher $\mathrm{C}$ & 74.1 \\
\hline Partner & & 86.2 \\
\hline Children & & 70.7 \\
\hline \multirow[t]{7}{*}{ Profession } & Psychologist/Psychiatrist & 20.7 \\
\hline & Social Worker & 18.1 \\
\hline & Nurse & 12.9 \\
\hline & Other Clinical & 6.0 \\
\hline & Security & 6.9 \\
\hline & $\begin{array}{l}\text { Consultancy and } \\
\text { Management }\end{array}$ & 24.1 \\
\hline & Secretarial and Administrative & 11.2 \\
\hline \multirow[t]{4}{*}{ Medical $^{\mathrm{D}}$} & $\mathrm{ASD}^{\mathrm{E}}$ & 2.6 \\
\hline & $\mathrm{ADHD}^{\mathrm{F}}$ & 4.3 \\
\hline & $\begin{array}{c}\text { Drugs or medication in last } 30 \\
\text { days }\end{array}$ & 6.9 \\
\hline & Neurological diseases & 4.3 \\
\hline
\end{tabular}

A Primary and special primary education, prevocational education, first three years of senior general secondary education and pre-university secondary education, lower secondary vocational training; ${ }^{\mathrm{B}}$ Upper secondary education, vocational training, middle management and specialist education; ${ }^{\mathrm{C}}$ Associate degree, bachelor degree, master degree, doctoral degree; ${ }^{\mathrm{D}}$ Variables known to be associated with sensory processing; ${ }^{\mathrm{E}} \mathrm{ASD}=$ autism spectrum disorder; ${ }^{\mathrm{F}} \mathrm{ADHD}=$ attention-deficit/hyperactivity disorder; ${ }^{\mathrm{G}}$ Drugs, which may influence sensory processing (e.g., antipsychotics, antidepressants, nausea medication or recreational drugs).

Perceived changes in work situation since the start of strict measures of social distancing, quarantine and lockdown in The Netherlands due to the COVID-19 pandemic in March 2020 are presented in Figure 1. Most of the participants in our sample experienced an increased level of workload. Moreover, a substantial part of the sample reported increased work-life conflicts and decreased effectiveness. Factors related to interaction with others partly showed decreased levels, although several employees (mainly working in inpatient settings) reported more involvement, feedback, social support, and appreciation by others. Approximately one third of our sample reported experiencing less pleasure in work, although job and financial security were perceived as fairly unchanged. Aggression-related incidents were reported as increased by a minority in the sample, mainly in the clinical setting. Finally, an increase in software problems was reported by almost half of the participants.

Means and standard deviations of all main measurements are presented in Table 2. In general, compared to the reference group of the AASP, our group of (predominantly healthy) workers was more often on the higher extremes of sensory sensitivity and sensory avoiding than expected. That means, more mental health professionals than expected reported to be hypersensitive to sensory stimuli and more mental health professionals than expected reported to avoid sensory stimulation. For perceived stress however, more participants in our sample than expected reported low stress (31\% vs. $15 \%)$ and fewer participants than expected reported high stress ( $8 \%$ vs. $15 \%$ ). On the burn-out scale, between $4.5 \%$ and $17.1 \%$ of participants in our sample reported the various (core or secondary) symptoms that indicate increased risk for burnout. 


\section{workload work-life conflict effectiveness autonomy}

involvement in decision-making feedback received from colleagues or supervisor social support from colleagues perceived appreciation from others work pleasure job satisfaction incidents with aggression from others software problems

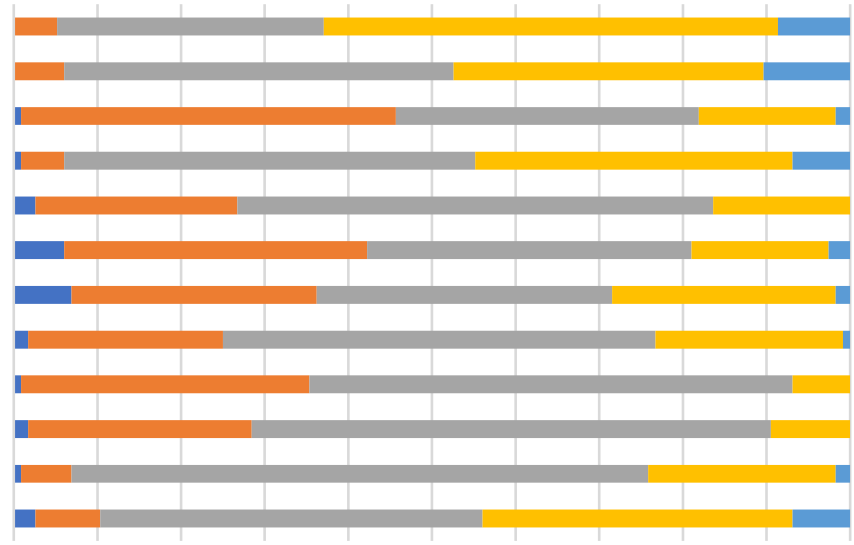

ఐ strongly decreased $\square$ decreased $\square$ not changed $\square$ increased $\square$ strongly increased

Figure 1. Perceived degree of changes in work situation since the Dutch COVID-19 measures of March 2020.

Table 2. Means and standard deviations of all involved total and subscale scores.

\begin{tabular}{|c|c|c|c|c|c|c|c|}
\hline \multirow{2}{*}{$\begin{array}{c}\text { Instrument } \\
\text { AASP }^{B}\end{array}$} & \multirow[t]{2}{*}{ Score } & \multirow[t]{2}{*}{$M(S D)$} & \multicolumn{5}{|c|}{ Comparison with Reference Group Data (\%) } \\
\hline & & & -- & - & $=$ & + & ++ \\
\hline & Low registration & $29.4(6.0)$ & 3.8 & 11.3 & 67.0 & 17.0 & 0.9 \\
\hline & Sensory seeking & $50.1(6.6)$ & 2.7 & 10.0 & 70.0 & 17.3 & 0.0 \\
\hline & Sensory sensitivity & $35.2(8.2)$ & 0.0 & 12.4 & 66.7 & 13.3 & 7.6 \\
\hline & Sensory avoiding & $36.34(8.5)$ & 1.9 & 7.5 & 67.3 & 15.0 & 8.4 \\
\hline & Total score & $150.9(19.5)$ & A & A & A & A & A \\
\hline \multirow[t]{4}{*}{ PSS } & & & \multicolumn{2}{|c|}{$<-1 \mathrm{SD}$} & \multicolumn{2}{|c|}{$=$} & $>+1 \mathrm{SD}$ \\
\hline & Perceived self-efficacy & $11.6(2.4)$ & \multicolumn{2}{|c|}{ A } & \multicolumn{2}{|c|}{$\bar{A}$} & A \\
\hline & Perceived helplessness & $6.1(4.1)$ & \multicolumn{2}{|c|}{$\mathrm{A}$} & \multicolumn{2}{|c|}{$\mathrm{A}$} & A \\
\hline & Perceived stress & $10.5(5.7)$ & \multicolumn{2}{|c|}{30.6} & \multicolumn{2}{|c|}{61.3} & 8.1 \\
\hline \multirow[t]{9}{*}{ BAT } & & & \multicolumn{2}{|c|}{ Low risk } & \multicolumn{2}{|c|}{ At risk } & Very high risk \\
\hline & Exhaustion & $2.0(0.6)$ & \multicolumn{2}{|c|}{95.5} & \multicolumn{2}{|c|}{1.8} & 2.7 \\
\hline & Mental distancing & $1.6(0.5)$ & \multicolumn{2}{|c|}{92.8} & \multicolumn{2}{|c|}{6.3} & 0.9 \\
\hline & Cognitive impairment & $1.9(0.5)$ & \multicolumn{2}{|c|}{94.6} & \multicolumn{2}{|c|}{3.6} & 1.8 \\
\hline & Emotional impairment & $1.7(0.5)$ & \multicolumn{2}{|c|}{82.9} & \multicolumn{2}{|c|}{13.5} & 3.6 \\
\hline & Core symptoms & $1.8(0.4)$ & \multicolumn{2}{|c|}{94.6} & \multicolumn{2}{|c|}{4.5} & 0.9 \\
\hline & Psychological complaints & $2.1(0.6)$ & \multicolumn{2}{|c|}{ A } & \multicolumn{2}{|c|}{ A } & A \\
\hline & Psychosomatic complaints & $1.9(0.7)$ & \multicolumn{2}{|c|}{ A } & \multicolumn{2}{|c|}{ A } & A \\
\hline & Secondary symptoms & $2.0(0.6)$ & \multicolumn{2}{|c|}{88.3} & \multicolumn{2}{|c|}{9.9} & 1.8 \\
\hline
\end{tabular}

${ }^{\text {A }}$ No reference group data available; ${ }^{\text {B }}$ AASP reference values range from - - 'much less than most people' to ++ 'much more than most people'.

\subsection{Regression Analysis}

Results of our primary multiple regression analyses are presented in Table 3. In general, sensory processing problems were associated with higher levels of perceived stress, with more core burnout symptoms and with more secondary burnout symptoms, with medium to large effect sizes. Individuals with higher scores on low registration (having problems to notice or detect changes in sensory situations) and on sensory sensitivity (having problems of hypersensitivity), perceived more stress and reported more burnout symptoms. 
Table 3. Multiple regression models with AASP raw quadrant and total scores, and stress- and burnout-related total scores.

\begin{tabular}{cccc}
\hline & Perceived Stress & Core Burnout Symptoms & Secondary Burnout Symptoms \\
\hline Low Registration & $b=0.262[0.071,0.453], p=0.008$ & $b=0.025[0.010,0.040], p=0.001$ & $\mathrm{~A}$ \\
Sensory Seeking & $\mathrm{A}$ & $\mathrm{A}$ & $\mathrm{A}$ \\
Sensory Sensitivity & $b=0.156[0.013,0.300], p=0.033$ & $b=0.012[0.001,0.023], p=0.038$ & $b=0.041[0.028,0.053], p<0.001$ \\
Sensory Avoiding & $\mathrm{A}$ & $\mathrm{A}$ & $\mathrm{A}$ \\
Effect Size $^{\mathrm{B}}$ & $f^{2}=0.26$ & $f^{2}=0.33$ & $f^{2}=0.41$ \\
\hline AASP Total Score & $b=0.123[0.071,0.174], p<0.001$ & $b=0.010[0.006,0.015], p<0.001$ & $b=0.018[0.013,0.023], p<0.001$ \\
Effect Size $^{\text {B }}$ & $f^{2}=0.23$ & $f^{2}=0.26$ & $f^{2}=0.48$ \\
\hline
\end{tabular}

Note. All regression models were adjusted for covariates sex, age and educational level. ${ }^{\mathrm{A}}$ Variable excluded from analysis after application of the forward selection method. ${ }^{\text {B }}$ Effect size of $\Delta R^{2}$ after adding predictor variable(s) in the second block in comparison to the covariates in the first block.

Table 4 shows that sensory processing problems were associated with all stress- and burnout-related subscale scores separately. Largest effect sizes were seen for psychological and psychosomatic complaints and exhaustion in relation to sensory sensitivity and low registration.

Table 4. Multiple regression models with AASP raw quadrant and total scores, and stress- and burnout-related subscale scores.

\begin{tabular}{|c|c|c|c|c|c|c|c|c|}
\hline & $\begin{array}{c}\text { Perceived } \\
\text { Self-Efficacy }\end{array}$ & $\begin{array}{c}\text { Perceived } \\
\text { Helplessness }\end{array}$ & Exhaustion & $\begin{array}{c}\text { Mental } \\
\text { Distancing }\end{array}$ & $\begin{array}{c}\text { Cognitive } \\
\text { Impairment }\end{array}$ & $\begin{array}{c}\text { Emotional } \\
\text { Impairment }\end{array}$ & $\begin{array}{l}\text { Psychological } \\
\text { Complaints }\end{array}$ & $\begin{array}{l}\text { Psychosomatic } \\
\text { Complaints }\end{array}$ \\
\hline Low Registration & A & $\begin{array}{c}b=0.260 \\
{[0.140,0.380]} \\
p<0.001\end{array}$ & $\begin{array}{c}b=0.025 \\
{[0.006,0.043]} \\
p=0.010\end{array}$ & A & $\begin{array}{c}b=0.039 \\
{[0.024,0.054]} \\
p<0.001\end{array}$ & $\begin{array}{c}b=0.029 \\
{[0.014,0.045]} \\
p<0.001\end{array}$ & $\begin{array}{c}b=0.023 \\
{[0.002,0.045]} \\
p=0.034\end{array}$ & A \\
\hline Sensory Seeking & A & $\mathrm{A}$ & $\mathrm{A}$ & A & $\mathrm{A}$ & $\mathrm{A}$ & $\mathrm{A}$ & A \\
\hline Sensory Sensitivity & $\begin{array}{c}b=-0.095 \\
{[-0.143,-0.047]} \\
p<0.001\end{array}$ & A & $\begin{array}{c}b=0.022 \\
{[0.008,0.036]} \\
p=0.002\end{array}$ & $\begin{array}{c}b=0.015 \\
{[0.002,0.027]} \\
p=0.020\end{array}$ & A & A & $\begin{array}{c}b=0.026 \\
{[0.010,0.042]} \\
p=0.002\end{array}$ & $\begin{array}{c}b=0.046 \\
{[0.032,0.060]} \\
p<0.001\end{array}$ \\
\hline Sensory Avoiding & $p<{ }_{\mathrm{A}}$ & A & $p-\underset{\mathrm{A}}{0.002}$ & $p-\underset{A}{0.020}$ & A & A & $p-{ }_{\mathrm{A}}^{\mathrm{U}} .002$ & $p<{ }_{\mathrm{A}}$ \\
\hline Effect Size ${ }^{B}$ & $f^{2}=0.16$ & $f^{2}=0.19$ & $f^{2}=0.37$ & $f^{2}=0.06$ & $f^{2}=0.27$ & $f^{2}=0.14$ & $f^{2}=0.32$ & $f^{2}=0.42$ \\
\hline AASP Total Score & $\begin{array}{c}b=-0.037 \\
{[-0.058,-0.017]} \\
p<0.001 \\
f^{2}-013\end{array}$ & $\begin{array}{c}b=0.085 \\
{[0.047,0.123]} \\
p<0.001 \\
f^{2}=020\end{array}$ & $\begin{array}{c}b=0.014 \\
{[0.009,0.019]} \\
p<0.001 \\
f^{2}-0.8\end{array}$ & $\begin{array}{c}b=0.006 \\
{[0.001,0.012]} \\
p=0.014 \\
f^{2}\end{array}$ & $\begin{array}{c}b=0.012 \\
{[0.007,0.016]} \\
p<0.001 \\
f^{2}-0.23\end{array}$ & $\begin{array}{c}b=0.007 \\
{[0.002,0.012]} \\
p=0.005 \\
f^{2}=0.08\end{array}$ & $\begin{array}{c}b=0.017 \\
{[0.011,0.023]} \\
p<0.001 \\
f^{2}\end{array}$ & $\begin{array}{c}b=0.019 \\
{[0.013,0.025]} \\
p<0.001 \\
f^{2}\end{array}$ \\
\hline Effect Size ${ }^{B}$ & $f^{2}=0.13$ & $f^{2}=0.20$ & $f^{2}=0.28$ & -006 & $f^{2}=0.23$ & $f^{2}=0.08$ & $f^{2}=0.36$ & $f^{2}=0.41$ \\
\hline
\end{tabular}

Note. All regression models were adjusted for covariates sex, age and educational level. ${ }^{A}$ Variable excluded from analysis after application of the forward selection method. ${ }^{\mathrm{B}}$ Effect size of $\Delta R^{2}$ after adding predictor variable(s) in the second block in comparison to the covariates in the first block.

As a post-hoc sensitivity analysis, the primary multiple regression analyses, as presented in Table 3, were repeated after exclusion of individuals with known medical conditions that are related to sensory problems (ASD, ADHD, neurological disease, or $\mathrm{drug} /$ medication use; $n=15$ ), see Table 5 . In the population without these medical conditions, we still found that low registration was related to perceived stress and core symptoms of burnout, and that hypersensitivity was related to secondary symptoms of burnout. Overall, associations remained statistically significant, although effect sizes were smaller.

Table 5. Multiple regression models with AASP raw quadrant and total scores, and stress- and burnout-related total scores in healthy population.

\begin{tabular}{cccc}
\hline & Perceived Stress & Core Symptoms Burnout & Secondary Symptoms Burnout \\
\hline Low Registration & $b=0.337[0.152,0.522], p<0.001$ & $b=0.030[0.016,0.045], p<0.001$ & $\mathrm{~A}$ \\
Sensory Seeking & $\mathrm{A}$ & $\mathrm{A}$ & $\mathrm{A}$ \\
Sensory Sensitivity & $\mathrm{A}$ & $\mathrm{A}$ & $\mathrm{A}=0.036[0.021,0.051], p<0.001$ \\
Sensory Avoiding & $\mathrm{A}$ & $f^{2}=0.21$ & $\mathrm{~A}$ \\
Effect Size $^{\mathrm{B}}$ & $f^{2}=0.16$ & $b=0.009[0.005,0.014], p<0.001$ & $b=0.016[0.010,0.022], p<0.001$ \\
\hline AASP Total Score & $b=0.109[0.051,0.168], p<0.001$ & $f^{2}=0.20$ & $f^{2}=0.34$ \\
Effect Size ${ }^{\mathrm{B}}$ & $f^{2}=0.16$ & & \\
\hline
\end{tabular}

Note. All regression models were adjusted for covariates sex, age and educational level. ${ }^{\text {A }}$ Variable excluded from analysis after application of the forward selection method. ${ }^{\text {B }}$ Effect size of $\Delta R^{2}$ after adding predictor variable(s) in the second block in comparison to the covariates in the first block. 


\section{Discussion}

In the present study, we explored the association between sensory processing on the one hand and perceived stress and burnout symptomatology on the other hand in a working population during a highly demanding crisis period. Our results indicate that both sensory sensitivity and low registration are relevant in this context. Hypersensitivity for sensory stimuli was associated with more stress, more core symptoms of burnout, such as exhaustion, mental distancing and cognitive and emotional impairment, and more secondary symptoms of burnout, such as psychological and psychosomatic complaints. Under registration of sensory stimuli was associated with more stress and more core symptoms of burnout. Effect sizes of these associations were medium to large. Posthoc sensitivity analysis revealed that correction for medical conditions, such as ASD, $\mathrm{ADHD}$, or medication use, reduced effect sizes, however did not fully explain the found associations. On a more detailed level of stress perception, hypersensitivity was associated with lower levels of perceived self-efficacy, whereas under-registration of sensory stimuli were associated with higher levels of perceived helplessness.

Our results are in line with earlier studies on sensory sensitivity and perceived stress [11-16]. Whereas previous research was often done in clinical (child) populations of patients with neurodevelopmental symptomatology, with known medical conditions that influence sensory processing as well as coping with stress, our study shows that sensory processing is also related to perceived stress in healthy workers. Our results add to recent studies that focused on the association of sensory processing sensitivity and occupational burnout [20,21]. Risk of burnout is not only heightened by the more static vulnerability of personality traits such as 'hypersensitive persons', but is probably also increased in individuals with neurodevelopmental difficulties in sensory processing. Next, sensory processing difficulties could be considered as a potential part of burnout symptomatology or sequelae.

Although our study design limits causal inference, the more detailed measurement of sensory processing, stress and burnout enables us to cautiously explore hypothetical causal explanations. Largest effect sizes were seen in the associations of sensory sensitivity with psychological and psychosomatic complaints of occupational burnout. To some extent, these concepts might show overlap. It is tempting to speculate that psychosomatic complaints are related to interoception, the perception of bodily sensations, which is not assessed in the AASP questionnaire. Previous research suggests that the altered interoception may result from acute or chronic stress [33]. This (over) awareness of internal stimuli as a result of perceived stress might also apply to the other, more externally directed senses. This activation of all senses in reaction to stress seems evolutionary intuitive. On an item level, psychological complaints of burnout are operationalized by sleeping problems, anxiety, and problems with crowdedness and noise. Clearly, this last item might have conceptual overlap with sensory sensitivity to auditory stimuli. However, in addition to the suggested conceptual overlap, sensory processing difficulties could also be a transdiagnostic factor in relation to psychological complaints. In particular, experiencing heightened levels of sensory sensitivity resulting from chronic stress could eventually be exhausting and, thus, cause sleeping problems. Finally, under registration of external stimuli-low registration-could well be related to or perhaps result from problems with concentration and attention as signs of burnoutrelated cognitive impairment. More research is needed to unravel the exact underlying causal mechanisms in place.

The Oostwest Project data collection started in June and was completed in August 2020. These summer months cover the tail of the 'first wave' of coronavirus infections and government measures in The Netherlands, including social distancing, the closing of schools and childcare centers, cafes and restaurants, and sport clubs, and the urgent advice to work from home. As a result, some employees in the study sample were advised or obliged to work from home, while others could continue their clinical work in institutions with in-patient populations suffering severe mental illness, which could be exaggerated by the presence of the stressful psychosocial factor amid COVID-19. For many out-patient 
mental healthcare workers, it resulted in increased application of telepsychiatry, a worldwide phenomenon [34]. Our population reported increased problems on various aspects related to the individual work situation in this challenging, demanding, and downright tough period for caregivers and other employees. These circumstances could have resulted in more variance on stress- and burnout-related variables, whereas social distancing overall might decrease levels of sensory stimulation. Although we did not observe high numbers of employees facing occupational burnout during our measurement, it is possible that many continued to have high job demands and low job positives, eventually leading to more burnouts during the following phases of the pandemic.

Whether our results are generalizable to other (working and non-working) populations is largely unknown. Due to the healthy worker effect [35], morbidity in our source population was assumed to be decreased in comparison with the general population. However, reported sensory-related factors, such as ASD or ADHD, seem to be as prevalent as or even more prevalent in our sample in comparison to the general population. A second limitation is the potential risk for selection bias. Selective non-response could have led to both over- or underestimation of perceived stress and/or burnout symptomatology. It is however unknown whether the found associations with sensory processing difficulties might be different in those non-responded. Third, the risk for information bias cannot be ruled out, as we used self-report measures for both determinants and outcomes. Finally, we assume the inclusion of covariates and the executed sensitivity analyses have addressed potential confounding effects, however residual confounding can never be ruled out.

\section{Conclusions}

Our study underscores the relevance of sensory processing in general and specific sensory processing patterns in perceived stress, occupational burnout and potentially a broad spectrum of mental health conditions [3]. Problems in sensory processing are highly related to psychological and psychosomatic burnout complaints, which indicates that sensory processing, particularly hypersensitivity, is a transdiagnostic factor for psychopathology. More research is needed to thoroughly investigate the specific role of sensory processing in mental health. From a more clinical or occupational point of view, our results suggest a bidirectional approach. First, for employees who experience sensory processing difficulties, it is important to be aware of stress- and burnout-related problems. Second, employers do well to create a healthy working environment by paying attention to sensory processing patterns and difficulties in their employees and, as a result, regulate the levels of input on all senses. Employers can offer awareness on the subject, as well as personal (e.g., occupational diagnostics and therapeutic interventions) and environmental (e.g., acoustics, smell and lighting within the work space) prevention and support.

Author Contributions: Conceptualization, F.v.d.B., P.S., B.S., Y.H.A.B. and S.J.R.; Data curation, F.v.d.B. and P.S.; Formal analysis, F.v.d.B., P.S. and S.J.R.; Funding acquisition, Y.H.A.B., W.J.G.H. and S.J.R.; Investigation, F.v.d.B., P.S. and Y.H.A.B.; Methodology, F.v.d.B., P.S. and S.J.R.; Project administration, F.v.d.B. and P.S.; Resources, F.v.d.B. and P.S.; Software, F.v.d.B. and P.S.; Supervision, Y.H.A.B., W.J.G.H. and S.J.R.; Validation, F.v.d.B., B.S., Y.H.A.B., W.J.G.H. and S.J.R.; Visualization, F.v.d.B. and P.S.; Writing—original draft, F.v.d.B.; Writing—review and editing, P.S., B.S., Y.H.A.B., W.J.G.H. and S.J.R. All authors have read and agreed to the published version of the manuscript.

Funding: This research was funded by Stichting Vrienden van Oldenkotte, Deventer, The Netherlands, grant number FORETECH.

Institutional Review Board Statement: The study was conducted in accordance with the Declaration of Helsinki, and approved by the Institutional Review Board of Dimence Group (CWO-062020PSFB).

Informed Consent Statement: Informed consent was obtained from all subjects involved in the study.

Data Availability Statement: The data presented in this study are available on request from the corresponding author. The data are not publicly available due to privacy regulations.

Acknowledgments: Our sincere gratitude goes out to all professionals at Dimence Group. 
Conflicts of Interest: The authors declare no conflict of interest. The funders had no role in the design of the study; in the collection, analyses, or interpretation of data; in the writing of the manuscript, or in the decision to publish the results.

\section{References}

1. Miller, L.J.; Lane, S.J. Toward a consensus in terminology in sensory integration theory and practice: Part 1: Taxonomy of neurophysiological processes. Sens. Integr. Spec. Interest Sect. Q. 2000, 23, 1-4.

2. Miller, L.J.; Anzalone, M.E.; Lane, S.J.; Cermak, S.A.; Osten, E.T. Concept evolution in sensory integration: A proposed nosology for diagnosis. Am. J. Occup. Ther. 2007, 61, 135-140. [CrossRef] [PubMed]

3. Brown, C.; Karim, R.; Steuter, M. Retrospective analysis of studies examining sensory processing preferences in people with a psychiatric condition. Am. J. Occup. Ther. 2020, 74, 7404205130p1-7404205130p11. [CrossRef] [PubMed]

4. American Psychiatric Association. Diagnostic and Statistical Manual of Mental Disorders, 5th ed.; American Psychiatric Publishing: Washington, DC, USA, 2013.

5. Engel-Yeger, B.; Dunn, W. The relationship between sensory processing difficulties and anxiety level of healthy adults Br. J. Occup. Ther. 2011, 74, 210-216. [CrossRef]

6. Engel-Yeger, B.; Dunn, W. Exploring the relationship between affect and sensory processing patterns in adults. Br. J. Occup. Ther. 2011, 74, 456-464. [CrossRef]

7. Ben-Avi, N.; Almagor, M.; Engel-Yeger, B. Sensory processing difficulties and interpersonal relationships in adults: An exploratory study. Psychology 2012, 3, 70. [CrossRef]

8. Engel-Yeger, B.; Shochat, T. The relationship between sensory processing patterns and sleep quality in healthy adults. Can. J. Occup. Ther. 2012, 79, 134-141. [CrossRef]

9. Engel-Yeger, B.; Dunn, W. Relationship between pain catastrophizing level and sensory processing patterns in typical adults Am. J. Occup. Ther. 2011, 65, e1-e10. [CrossRef]

10. Costa-López, B.; Ferrer-Cascales, R.; Ruiz-Robledillo, N.; Albaladejo-Blázquez, N.; Baryła-Matejczuk, M. Relationship between sensory processing and quality of life: A systematic review. J. Clin. Med. 2021, 10, 3961. [CrossRef]

11. Corbett, B.A.; Schupp, C.W.; Levine, S.; Mendoza, S. Comparing cortisol, stress, and sensory sensitivity in children with autism Autism Res. 2009, 2, 39-49. [CrossRef]

12. Corbett, B.A.; Muscatello, R.A.; Blain, S.D. Impact of sensory sensitivity on physiological stress response and novel peer interaction in children with and without autism spectrum disorder. Front. Neurosci. 2016, 10, 278. [CrossRef] [PubMed]

13. Reynolds, S.; Lane, S.J.; Gennings, C. The moderating role of sensory Overresponsivity in HPA activity: A pilot study with children diagnosed with ADHD. J. Atten. Disord. 2010, 13, 468-478. [CrossRef] [PubMed]

14. Amos, G.A.; Byrne, G.; Chouinard, P.A.; Godber, T. Autism Traits, Sensory Over-Responsivity, Anxiety, and Stress: A Test of Explanatory Models. J. Autism Dev. Disord. 2019, 49, 98-112. [CrossRef] [PubMed]

15. Callahan, M.L.; Storzbach, D. Sensory sensitivity and posttraumatic stress disorder in blast exposed veterans with mild traumatic brain injury. Appl. Neuropsychol. Adult 2019, 26, 365-373. [CrossRef]

16. Yochman, A.; Pat-Horenczyk, R. Sensory modulation in children exposed to continuous traumatic stress. J. Child Adolesc. Trauma 2020, 13, 93-102. [CrossRef]

17. Brown, C.; Tollefson, N.; Dunn, W.; Cromwell, R.; Filion, D. The adult sensory profile: Measuring patterns of sensory processing Am. J. Occup. Ther. 2001, 55, 75-82. [CrossRef]

18. Canu, I.G.; Marca, S.C.; Dell'Oro, F.; Balázs, Á.; Bergamaschi, E.; Besse, C.; Bianchi, R.; Bislimovska, J.; Bjelajac, A.K.; Bugge, M. Harmonized definition of occupational burnout: A systematic review, semantic analysis, and Delphi consensus in 29 countries. Scand. J. Work Environ. Health 2021, 47, 95. [CrossRef]

19. Schaufeli, W.B.; Desart, S.; De Witte, H. Burnout Assessment Tool (BAT)—Development, validity, and reliability. Int. J. Environ. Res. Public Health 2020, 17, 9495. [CrossRef]

20. Meyerson, J.; Gelkopf, M.; Eli, I.; Uziel, N. Burnout and professional quality of life among Israeli dentists: The role of sensory processing sensitivity. Int. Dent. J. 2020, 70, 29-37. [CrossRef]

21. Pérez-Chacón, M.; Chacón, A.; Borda-Mas, M.; Avargues-Navarro, M.L. Sensory processing sensitivity and compassion satisfaction as risk/protective factors from burnout and compassion fatigue in healthcare and education professionals. Int. J. Environ. Res. Public Health 2021, 18, 611. [CrossRef]

22. Aron, E.N.; Aron, A.; Jagiellowicz, J. Sensory processing sensitivity: A review in the light of the evolution of biological responsivity. Pers. Soc. Psychol. Rev. 2012, 16, 262-282. [CrossRef] [PubMed]

23. Dunn, W. The impact of sensory processing abilities on the daily lives of young children and their families: A conceptual model. Infants Young Child 1997, 9, 23-35. [CrossRef]

24. Brown, C.; Dunn, W. Adolescent/Adult Sensory Profile; Pearson: San Antonio, TX, USA, 2002.

25. Rietman, A. Adolescent/Adult Sensory Profile-NL: User's Manual; Harcourt Test Publishers: San Diego, CA, USA, 2007.

26. DuBois, D.; Lymer, E.; Gibson, B.E.; Desarkar, P.; Nalder, E. Assessing sensory processing dysfunction in adults and adolescents with autism spectrum disorder: A scoping review. Brain Sci. 2017, 7, 108. [CrossRef] [PubMed]

27. Technical Report: Adolescent/Adult Sensory Profile. 2008. Available online: http://images.pearsonassessments.com/images/ tmrs/tmrs_rg/AD_Adult_SP_TR_Web.pdf?WT.mc_id=TMRS_Adolescent_Adult_Sensory_Profile (accessed on 15 January 2018) 
28. Cohen, S.; Kamarck, T.; Mermelstein, R. Perceived stress scale. Meas. Stress Guide Health Soc. Sci. 1994, 10, 1-2.

29. Cohen, S. Perceived stress in a probability sample of the United States. In The Social Psychology of Health; Spacapan, S., Oskamp, S., Eds.; Sage Publications Inc.: Newbury Park, CA, USA, 1988.

30. Cohen, S.; Kamarck, T.; Mermelstein, R. A global measure of perceived stress. J. Health Soc. Behav. 1983, 24, 385-396. [CrossRef]

31. Schaufeli, W.B.; De Witte, H.; Desart, S. Handleiding Burnout Assessment Tool (BAT). KU Leuven België Intern. Rapp. 2019. Available online: https://burnoutassessmenttool.be/project_eng/\#handleidingenvragenlijst (accessed on 28 April 2020).

32. Cohen, J. Statistical Power Analysis for the Behavioral Sciences; Academic Press: Cambridge, MA, USA, 2013.

33. Schulz, A.; Vogele, C. Interoception and stress. Front. Psychol. 2015, 6, 993. [CrossRef]

34. Shore, J.H.; Schneck, C.D.; Mishkind, M.C. Telepsychiatry and the coronavirus disease 2019 pandemic-Current and future outcomes of the rapid virtualization of psychiatric care. JAMA Psychiatry 2020, 77, 1211-1212. [CrossRef]

35. McMichael, A.J. Standardized mortality ratios and the "healthy worker effect": Scratching beneath the surface. J. Occup. Med. 1976, 18, 165-168. [CrossRef] 